\title{
O Esquema da Quantidade em Kant e suas relações com Aristóteles e Platão
}

\section{The Quantity concept in Kant and its relations with Aristotle and Plato}

\author{
Gilfranco Lucena dos Santos* \\ Recebido: 02/2016 \\ Aprovado: 03/2016
}

\begin{abstract}
Resumo: Este artigo visa elucidar a compreensão kantiana do esquema da quantidade e estabelecer suas relações possíveis entre a compreensão aristotélica e platônica do conceito de quantidade.

Palavras-chave: Kant, Esquema, Quantidade, Platão, Aristóteles.

Abstract: This article aims to elucidate the kantian comprehension of the concept of quantity and to stablish its possible relation with Aristotle's and Plato's concept of quantity.

Key-words: Kant, Quantity, Aristotle, Plato.
\end{abstract}

Na Crítica da Razão Pura, na exposição da Doutrina do Esquematismo Transcendental, Kant assegura que "o esquema puro da quantidade (quantitatis) como conceito do entendimento é o número, que é uma representação que enfeixa a sucessiva adição de um a um (homogêneos)" (KANT, KrV, A142/B182) ${ }^{1}$. Para uma cuidadosa interpretação do que aqui se exprime, importa que se pergunte: o que é um esquema? Donde advém a compreensão do número como uma "representação que enfeixa a sucessiva adição de um a um"?

Para falar em esquema, convém ingressarmos dentro do contexto em que se expõe a Doutrina do Esquematismo Transcendental, na qual o conceito de esquema emerge.

Segundo Kant, "em todas as subsunções de um objeto a um conceito" (KrV, A137/B176), a representação do objeto (Gegenstand) deve ser equiparável à do conceito de modo que o conceito possa "conter o que é representado no objeto a ser

* Bacharel e Mestre em Filosofia pela Universidade Federal de Pernambuco e Doutor em Filosofia pela Universidade Ferderal da Paraíba. Professor do Departamento de Filosofia da Universidade Federal da Paraíba. 
subsumido a ele" ( $K r V$, A137/B176), uma vez que é justamente assim que se constitui o significado do fato de que um objeto esteja subsumido a um conceito. Kant nos dá um exemplo relevante, curioso e importante para compreendermos o que ele está querendo dizer: o conceito empírico de um prato se equipara ao conceito geométrico puro de um círculo, uma vez que a redondez (rotundidade), que é pensada no primeiro, deixa-se mostrar (anschauen) no círculo (Cf. KANT, KrV, A137/B176). Mas, como os conceitos puros do entendimento não se equiparam a nada que se deixe mostrar sensivelmente (visivelmente), não podendo ser jamais encontradas em uma mostração (intuição), como então se faz possível a aplicação das categorias, isto é, dos conceitos puros do entendimento, aos fenômenos que se mostram sensivelmente segundo as formas espaço-temporais?

Kant entende que é preciso haver um terceiro elemento que se equipare, de um lado, à categoria e, de outro, ao fenômeno, "tornando possível a aplicação da primeira ao último" $(\mathrm{KrV}$, A138/B177). Para Kant, o esquema transcendental é esta representação mediadora pura, que não contém nada de empírico e, não obstante, por um lado, pode ser pensada intelectualmente e, por outro, pode ser mostrada sensivelmente.

O esquema é compreendido por Kant como "a representação de um procedimento geral da capacidade imaginativa de fornecer a um conceito a sua imagem" $(\mathrm{KrV}$, A140/B179-180). Mas aqui há que se distinguir o esquema da imagem. "A imagem (Bild), diz Kant, é um produto da capacidade (Vermögens) empírica do poder de imaginação produtiva" ( $\mathrm{KrV}$, A141/B181), ou seja: a imagem que figuramos em formas e cores e percebemos pelos sentidos e trazemos na lembrança. Já "o esquema" é dito "dos conceitos sensíveis" puros "(como as figuras no espaço)", e "é um produto e igualmente um monograma do poder de imaginação puro a priori, através do qual e de acordo com o qual as imagens se tornam primeiro que tudo possíveis" ( $K r V$, A141-142/B181). Porém, essas imagens, tornadas possíveis pelos esquemas dos conceitos sensíveis puros, têm que estar sempre conectadas com os conceitos somente por meio do esquema que caracterizam, sendo que em si mesmas "não são plenamente congruentes com o conceito" ( $K r V$, A142/B181). Por exemplo, um círculo desenhado ou perfilado em um objeto nunca é plenamente congruente com o conceito de círculo.

Então Kant mostra que "o esquema de um conceito puro do entendimento é algo que, de modo algum pode ser trazido à tona 
em uma imagem", sendo "somente a síntese pura conforme uma regra da unidade segundo conceitos em geral, que exprime a categoria", e sendo, além disso, "um produto do poder transcendental de imaginação, a qual concerne à determinação do sentido interno em geral, segundo condições de sua forma (tempo), em vista de todas as representações, na medida em que estas devem conectar-se a priori a um conceito conforme a unidade da apercepção" ( $K r V$, A142/B181). Vale recordar que, para Kant, a apercepção é a capacidade do pensamento de reunir em um conceito o múltiplo dado na intuição.

Assim, o esquema tanto é regra como produto da capacidade transcendental de imaginação. "Visto a partir do entendimento, o esquema é a regra para o proceder da capacidade imaginativa, que, como tal, não existe em outro lugar senão no pensamento" . Por outro lado, "visto a partir da sensibilidade, o esquema é a unidade do dado sensível e, como tal, um produto da atividade da capacidade imaginativa" 3 .

Desse modo, a capacidade imaginativa constitui imagem em sentido empírico e em sentido puro. A imagem em sentido empírico, como vimos, é um produto da capacidade empírica do poder de imaginação produtiva. Por exemplo, quando desenhamos o círculo com compasso, ou representamos o número cinco através de um conjunto de pontos etc., estamos produzindo imagens em sentido empírico de acordo com o poder da imaginação produtiva. Há, porém, imagem em sentido puro, às quais Kant denomina esquemas.

Sem querer se deter no que seria, segundo ele, uma "monótona e árida decomposição do que é requerido para os esquemas transcendentais em geral de conceitos puros do entendimento" ( $K r V$, A142/B181), Kant passa a uma "mera" apresentação dos mesmos "segundo a ordem das categorias e em conexão com elas" ( $K r V$, A142/B181), e introduz a apresentação do esquema segundo a categoria de quantidade.

De início, Kant diz que o espaço é "a imagem pura de todas as quantidades (quantorum) ante o sentido externo" ( $\mathrm{KrV}$, A142/B182), ao passo que o tempo se constitui na imagem pura "de todos os objetos dos sentidos em geral" ( $K r V$, A142/B182).

Pensemos primeiro no espaço: o que quereria dizer Kant, tendo em vista o que já compreendemos por imagem pura ou esquema, que o espaço seja a imagem pura de todas as quantidades (quantorum) ante o sentido externo? Kant não o elucida, e, por isso, aqui nos situamos em um ponto da doutrina 
do esquematismo transcendental que exige uma explicação esclarecedora, uma interpretação pautada na compreensão que podemos ter dessa assertiva.

Primeiro que tudo, é preciso dizer que, enquanto imagem pura (reine Bild), o espaço é, aqui, um conceito do pensamento, e não se confunde com a intuição (Anschauung) da sensibilidade externa, que se constitui na forma externa da aparição sensível. Por que? Primeiro, porque se trata de uma regra segundo a qual o múltiplo da intuição é reunido num conceito; e, segundo, porque é um produto da capacidade de imaginação, que fornece o esquema segundo o qual esse múltiplo pode ser subsumido a um conceito. O espaço se constitui como uma forma (Gestalt) ou grandeza em geral (allgemeine Größe) segundo a qual o conceito de quantidade pode ser aplicado a um dado do sentido externo (o espaço enquanto intuição pura).

Um excelente exemplo de como esse esquema do espaço se constitui conceitualmente pode ser mostrado por meio do modo como Aristóteles descreve a categoria de quantidade (Tò moбóv) em Metafísica $\Delta$ 13, 1020a 8-14; aí, Aristóteles fornece, interpretando desde uma perspectiva kantiana, o esquema para a aplicação da categoria de quantidade ao múltiplo dado na intuição do sentido externo, quando diz:

\footnotetext{
Uma multiplicidade é algo quanto se é numerável, e uma grandeza se é mensurável. E se chama múltiplo o potencialmente divisível em partes descontínuas, e grandeza o divisível em partes contínuas. E a grandeza contínua em uma dimensão se chama longitude; a contínua em duas, latitude, e a contínua em três, profundidade. E a multiplicidade finita se chama número, e a longitude, linha, e a latitude, superfície, e a profundidade, corpo. ${ }^{4}$ (ARISTÓTELES, Metafísica D 13,1020 a 8-14)
}

Ora, vê-se, pois, assim, como está constituído o espaço como imagem pura, e, portanto, como esquema, de todas as quantidades (quantorum) ante o sentido externo, apesar de, evidentemente não usar um conceito como espaço. Mas, curiosamente, já Aristóteles compreende a categoria de quantidade também na perspectiva espacial, a partir do conceito de grandeza $\left(\mu \dot{\varepsilon}^{\prime} \varepsilon \theta 0 s\right)$ em geral. Explicitada a compreensão aristotélica de maneira mais esquemática podemos apresentar o seguinte quadro ${ }^{5}$ : 


\begin{tabular}{|c|c|c|c|c|c|}
\hline & & mooóv & & & \\
\hline$\mu \eta{ }^{\prime} \sigma v \varepsilon \varepsilon \chi \eta$ & $\pi \lambda \hat{\eta} \theta$ os & & \multicolumn{2}{|c|}{$\mu \varepsilon^{\prime} \gamma \varepsilon \theta 0 s$} & 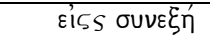 \\
\hline \multicolumn{2}{|c|}{$\alpha \dot{\rho} \rho \theta \mu \eta \dot{\tau} \tau$} & & \multicolumn{3}{|c|}{ Мвтрптоv } \\
\hline & & $\Pi \varepsilon \pi \varepsilon \rho \propto \sigma \mu \varepsilon \nu \circ \nu$ & & & \\
\hline & 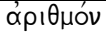 & & $\gamma \rho \propto \mu \mu \eta$ & $\mu \hat{n}$ KOS & 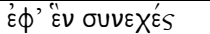 \\
\hline & & & $\varepsilon \pi \prime \phi \alpha ́ v \varepsilon ı \alpha$ & $\pi \lambda \alpha^{\prime} \operatorname{Tos}$ & 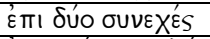 \\
\hline & & & $\sigma \omega \hat{\mu} \alpha$ & ßа́тоs & $\varepsilon \pi ।$ трI \\
\hline
\end{tabular}

\begin{tabular}{|c|c|c|c|c|c|}
\hline & & quantum $^{6}$ & & & \\
\hline non continua & multitudo & & \multicolumn{2}{|c|}{ magnitudo } & Continua \\
\hline \multicolumn{2}{|c|}{ numerabilis } & & \multicolumn{3}{|c|}{ Mensurabilis } \\
\hline \multicolumn{2}{|c|}{ numerabilis } & Finita & & & \\
\hline & numerus & & linea & longitudo & in unum continuum \\
\hline & & & superficies & latitudo & in duo continuo \\
\hline & & & corpus & profund & in tria continua \\
\hline
\end{tabular}

\begin{tabular}{|c|c|c|c|c|c|}
\hline & & quantidade & & & \\
\hline Descontínua & multiplicidade & & \multicolumn{2}{|c|}{ Grandeza } & Contínua \\
\hline \multicolumn{2}{|c|}{ enumerável } & & \multicolumn{3}{|c|}{ Mensurável } \\
\hline \multicolumn{6}{|c|}{ Finita } \\
\hline \multirow{2}{*}{\multicolumn{2}{|c|}{ número }} & & linha & longitude & \multirow{2}{*}{$\begin{array}{l}\text { contínua em uma } \\
\text { [dimensão] }\end{array}$} \\
\hline & & & & & \\
\hline & & & \multirow[t]{2}{*}{ superfície } & latitude & \multirow{2}{*}{$\begin{array}{l}\text { contínua em duas } \\
\text { [dimensões] }\end{array}$} \\
\hline & & & & & \\
\hline & & & corpo & profundidade & $\begin{array}{l}\text { contínua em três } \\
\text { [dimensões] }\end{array}$ \\
\hline
\end{tabular}

Se, porém, para Aristóteles, essas quantidades eram abstraídas a partir do ente subsistente em lugar natural, para Kant, o espaço está, assim, constituído como forma pura (e, neste sentido subjetiva e transcendental) da aparição externa de um dado sensível. Para Aristóteles, este dado era a matéria inteligível (quantidade mensurável) de uma determinada entidade (oưoí $\propto$ ), tal como, por exemplo, a rotundidade dada em um prato, ou, seguindo o exemplo do próprio Aristóteles, a circularidade dada na moeda de bronze. Com efeito, dizia Aristóteles:

[o matemático] especula eliminando previamente todas as qualidades sensíveis, como o peso e a leveza, a dureza e seu contrário, e também o calor e a frieza, e as demais contrariedades sensíveis, e só deixa a quantidade e a continuidade, de umas coisas, em uma dimensão, de outras, em duas, e de outras, em três, e considera as afecções destas coisas em sua qualidade de quantas e contínuas, e não em nenhum outro sentido, e de umas coisas considera as posições recíprocas e o que corresponde a estas, de outras a comensurabilidade ou a incomensurabilidade, de outras as relações proporcionais, e, sem embargo, dizemos que há uma só ciência de todas estas coisas, a Geometria. (Metafísica K 3, 1961a 28 - 1061b 3) 
Este processo de eliminação de todos os aspectos sensíveis

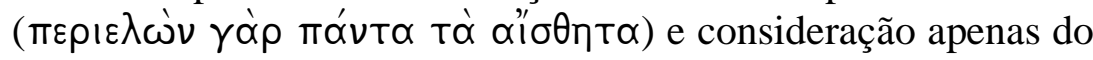
que se pode isolar como quantidade descontínua e quantidade contínua para compreender suas relações recíprocas é o que Aristóteles considera como próprio da abstração matemática. Este é o meio pelo qual se realiza a passagem do âmbito do sensível para o âmbito do inteligível, ainda que, como dizia Platão, ao tratar disso, o matemático se vale do sensível para demonstrar o que inteligivelmente discerne, por meio da percepção que distingue e separa aquilo que constituem as hipóteses matemáticas, através de nomes, definições e gráficos.

Ainda no livro K da Metafísica ele escreve: ó $\mu \alpha \theta \eta \mu \alpha$ тıкòs

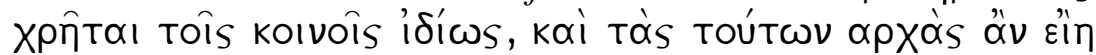

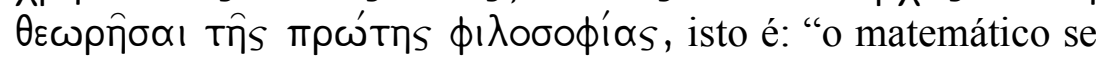
vale de noções comuns" - o que Platão denomina hipóteses ${ }^{7}$, que tanto podem ser definições, postulados ou axiomas - "e a especulação de seus princípios será própria da filosofia primeira" (Metafísica K 4, 1061b 17-19), o que Platão considerará próprio da dialética: partir das hipóteses para os princípios não hipotéticos

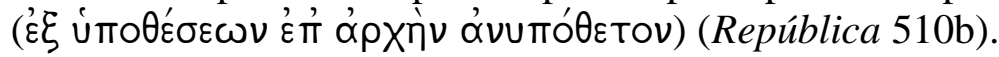

Porém, essa matéria inteligível não se estabelece, como para Kant, como condições de possibilidade subjetiva a priori de determinação objetiva do dado sensível, presente à intuição externa, mas são fruto de um processo de abstração matemática a partir da categoria de quantidade. Para Aristóteles:

... as coisas matemáticas nem são entidades em maior grau que os corpos nem são anteriores às coisas sensíveis enquanto ao ser, mas tão somente enquanto ao enunciado, nem é possível que existam separadas. $\mathrm{E}$, posto que, como vimos, tão pouco podem existir como pertencentes às coisas sensíveis, está claro que ou não são em absoluto ou são de certa maneira, e, por conseguinte, não se lhes pode atribuir o ser absolutamente. Ser, com efeito, o dizemos em vários sentidos ${ }^{8}$ (Metafísica M 2, 1077b 12-16).

Mas, o que seria para Kant esse dado sensível ao qual o perfil redondo do prato remonta, isto é, o círculo? O que seria esse dado sensível que se equipara à grandeza contínua em duas (superfície) do esquema do espaço como imagem pura em geral de todas as quantidades ante o sentido externo? Para Kant, ou melhor, na perspectiva do pensamento de Kant, o círculo é uma 
forma pura (reine Gestalt) independente do empírico e dado a priori na intuição como forma do sentido externo, segundo o esquema do espaço como imagem pura de todas as quantidades em geral ante o sentido externo. Assim, enquanto o espaço é a imagem pura da grandeza em geral, que fornece a regra de produção de imagem da capacidade de imaginação, e é, ao mesmo tempo, produto desta, o círculo é uma forma pura (Gestalt) a priori que, do ponto de vista do entendimento serve como regra da capacidade imaginativa e, do ponto de vista da sensibilidade, é uma imagem pura, que é, por sua vez, produto da capacidade imaginativa, e que não pode ser trazida à tona por nenhuma imagem empírica, o que estaria em perfeito acordo também com a posição platônica.

Na perspectiva platônica, círculo é o nome dado a uma hipótese (úmó $\theta \varepsilon \sigma \mid S$ ) fornecida em uma definição ou enunciado

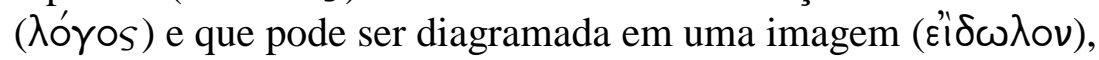
certamente sensível, e que, porém, jamais pode ser confundida com algo visível (óparóv); pois quando os matemáticos lançam mão de determinadas noções (sejam elas definições, postulados ou noções comuns) como supostos para poder em cada caso concluir definitivamente a respeito de determinadas proposições matemáticas, desenhando ( $\gamma \rho \propto \phi o v \sigma i ́ v)$ e servindo-se das figuras

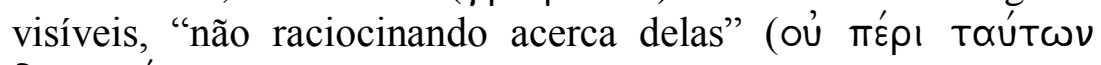

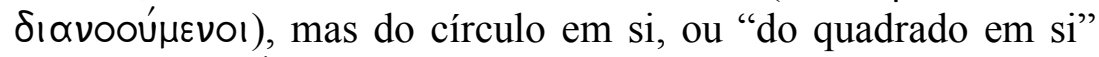

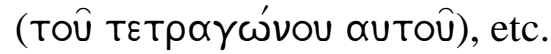

Todas as figuras que eles [os matemáticos ou geômetras]

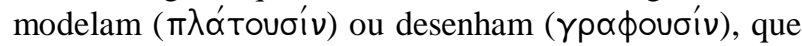

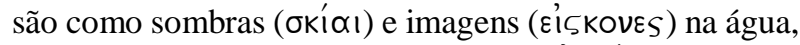

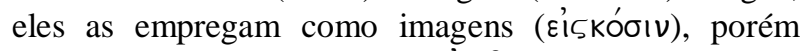

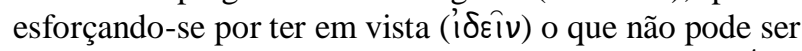

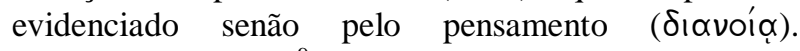
(República VI 510e $)^{9}$.

Na Carta Sétima, Platão assegura que: "São três [coisas] que necessariamente emergem em favor da compreensão dos entes singulares, [sendo o] quarto [ele] mesmo - quinto o que é ente conhecido e verdadeiro - um o nome, em segundo o enunciado [definidor], o terceiro a imagem, [e] quarto a

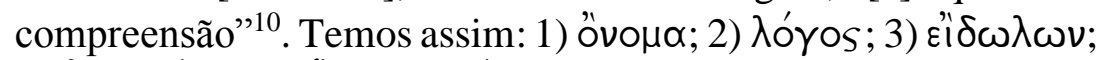
4) દ̇тıоти́ segundo, o enunciado definidor, o terceiro é a imagem sensível feita à luz desse enunciado, o quarto é o estar ciente desse fato e

Problemata: R. Intern. Fil. v.7, n. 1(2016), p 156-168 ISSN 2236-8612 
o quinto é o conhecido propriamente dito como princípio que mais importa. Para fornecer um exemplo paradigmático deste processo de constituição do conhecimento, Platão nos fornece o seguinte exemplo:

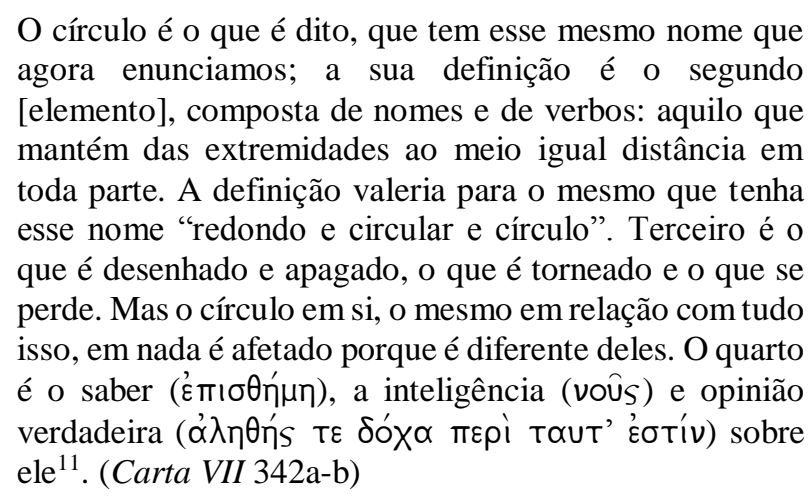

Podemos também considerar, e talvez efetivamente precisemos. O que significa que o esquema seja ao mesmo tempo regra e produto, e ainda como se deve compreender que, enquanto produto da capacidade de imaginação, este esquema é síntese da multiplicidade dada na intuição externa, isto é, o espaço, em que a sensação simultânea das partes (da multiplicidade dada na intuição) fornece o esquema da síntese desta multiplicidade, bem como síntese da intuição externa e interna, o tempo. Podemos verificar que os modos de conexão (ou síntese) da multiplicidade diferem considerando o múltiplo dado na intuição externa em geral e o múltiplo dado na intuição externa e interna. O múltiplo dado na intuição externa é simultâneo. O múltiplo dado na intuição interna e externa é sucessivo. Um "obedece" à regra da simultaneidade, ao passo que o outro obedece à regra da sucessão. Isso é o que diferencia o "objeto" da geometria do "objeto" da aritmética.

A partir de um exemplo, podemos destrinchar esse problema e elucida-lo. A "imagem empírica" do círculo, feita com compasso, é também constituída no tempo segundo uma regra de sucessão no movimento contínuo. Mas o círculo em si (em sentido platônico), ou seja, o círculo enquanto imagem pura e, portanto, enquanto esquema, é dado a priori no espaço e suas partes se constituem segundo uma regra de simultaneidade e não de sucessão (por exemplo, o centro e a extremidade do círculo são partes simultâneas no círculo que, inclusive, têm que estar dadas de antemão para que mesmo um círculo empírico possa ser

Problemata: R. Intern. Fil. v.7, n. 1(2016), p 156-168 ISSN 2236-8612 
constituído). Esse múltiplo reunido no conceito de círculo enquanto imagem pura (esquema) é, visto a partir do entendimento, dado a priori como regra da capacidade de imaginação através de sua definição, qual seja, a figura que mantém das extremidades ao meio igual distância em toda parte. É a sensação da simultaneidade dessas partes no espaço que, contudo, fornece a síntese desta multiplicidade no espaço, dando esta imagem pura como produto da capacidade de imaginação. Todas as partes desta imagem pura dada na intuição externa são equitemporâneas, isto é, simultâneas (gleichzeitig), portanto em referência à intuição externa. "A multiplicidade na sucessão é, como tal, justamente tomada não equitemporaneamente (simultaneamente, gleichzeitig)"12. Dito de maneira mais simples: a "imagem empírica" de um círculo, que na verdade é apenas uma representação a posteriori que não fornece o círculo como imagem pura, se deixa tomar, por referência ao tempo, segundo a sucessão; mas a imagem pura, isto é, o círculo enquanto esquema, tem suas partes simultaneamente dadas no espaço, seja do ponto de vista do entendimento, em que, por intermédio de conceitos, tem-se do círculo a regra fornecida pela capacidade de imaginação, seja do ponto de vista da sensibilidade, em que a sensação me fornece espacialmente o esquema como produto da capacidade de imaginação ${ }^{13}$. Justamente isto não acontecerá com o número. Mas para chegarmos a demonstrar isso, verifiquemos primeiro, por uma retomada, como o tempo se constitui no esquema de todos os objetos dados na intuição interna.

É preciso, porém, que se recorde que a sucessão no tempo é o esquema da causalidade, ao passo que a simultaneidade no tempo é o esquema da comunidade (Gemeinschaft, isto é, a ação recíproca entre o agente e o paciente). Sucessão e simultaneidade são, portanto, "determinações do tempo a priori segundo regras" (KANT, $K r V$, A145/B184), e constituem-se sobre a ordem do tempo (Zeitordnung). A sensação é o esquema da qualidade, e se constitui sobre o conteúdo do tempo. Desse modo se compreende porque mesmo os dados que aparecem segundo a forma do sentido externo são também determinações do tempo, na medida em que o múltiplo dado na intuição se constitui qualitativamente na sensação como esquema da qualidade fundada no conteúdo do tempo e relativamente na simultaneidade como esquema da comunidade fundada na ordem do tempo. Assim, os esquemas da sensação e da simultaneidade como determinações do conteúdo do tempo e da ordem do tempo determinam o dado fenomenal que aparece a priori sob a forma do sentido externo.

Problemata: R. Intern. Fil. v.7, n. 1(2016), p 156-168 ISSN 2236-8612 
Como o tempo se constitui na imagem pura de todos os objetos dos sentidos em geral, seus esquemas não se reduzem à sensação, mas tem também ainda o número, a permanência, a sucessão e todos os demais esquemas da modalidade. Como se deve entender, porém, que o número seja o esquema puro da quantidade na medida em que "é uma representação que enfeixa a sucessiva adição de um a um"?

Como regra da capacidade de imaginação, o número é concebido como a adição sucessiva de um a um, e se determina, portanto, segundo a regra da sucessão no tempo. Por outro lado, enquanto produto, mas sem o concurso da sensação, o número é concebido como a imagem pura que enfeixa em uma totalidade o múltiplo dado na sucessão. Como o número não é concebido segundo a regra (esquema) da sensação nem da simultaneidade, não se pode conceber que o número seja passível de ser dado sob a forma do sentido externo. E, se por um lado, tal como as figuras geométrica e seus elementos, que não podem ser concebidos como imagem empírica, o número sem é concebido sob a forma de uma imagem externa empírica nem a priori. O número é sem imagem.

Seguindo o que diz Heidegger a respeito disso: "Enquanto a imagem tem a figura de algo particular, o esquema tem "por objeto' a unidade da regra geral de múltiplas representações"14. Esta tese se aplica tanto aos esquemas geométricos como aso esquemas aritméticos e mesmo algébricos, poderíamos dizer; (pois os esquemas algébricos determinam a priori segundo regras, o modo como em geral, para vários casos particulares, esquemas aritméticos podem ser aplicados a esquemas geométricos). Um esquema geométrico, "por exemplo, um triângulo desenhado, há de ser forçosamente um acutângulo, um retângulo ou um obtusângulo"15. Desse modo, tal esquema tem por objeto fornecer a regra geral das múltiplas representações possíveis. Do mesmo modo, a imagem empírica e, portanto, não pura, de cinco pontos um ao lado do outro [...], ou de cinco faces de um sólido geométrico ou cinco lados de uma figura plana, não é sem pode ser a imagem pura ou esquema de número cinco, mas apenas uma representação empírica fornecida segundo essa regra. "O número mesmo não tem nunca o aspecto dos cinco pontos, porém tão pouco o dos signos 5 ou V."16. Diz Kant: "Na realidade, à base de nossos conceitos puros sensíveis não há imagens (aspectos imediatos) dos objetos, mas esquemas" ( $\mathrm{KrV}$, 
A140/B180). Assim, nem a imagem da série de pontos, nem de cinco lados de um pentágono, nem de cinco faces de um sólido, nem o signo 5 "constitui o aspecto verdadeiro que pertence estruturalmente ao esquema" ${ }^{17}$, mas a sucessiva adição de um a um enfeixada por esta quantidade definida.

Assim, se no esquema do círculo o que temos como produto da capacidade imaginativa é a unidade das múltiplas partes segundo o esquema da simultaneidade no tempo, no esquema do número o que temos como produto da capacidade imaginativa é a unidade das múltiplas partes reunidas segundo o esquema da sucessão no tempo. Enquanto as partes do círculo no espaço são simultâneas no tempo, as partes do número são sucessivas no tempo. Enquanto do círculo temos a sensação da simultaneidade de suas partes no espaço, do número não temos qualquer sensação, mas apenas a reunião de suas partes pela adição sucessiva de suas unidades no tempo, claro, porque reunidas (pensadas), enfeixadas em um número determinado, que serve de regra para qualquer representação numérica que lhe seja equivalente. Mas tanto os números como as formas subsistem previamente, isto é, ontologicamente a priori, como regra e produto da capacidade imaginativa, a qualquer representação imagética que lhe corresponda empiricamente. A adição sucessiva de um a um e a relação simultânea entre as partes determinam a priori os esquemas ou conceitos sensíveis puros da aritmética e da geometria, isto é, as regras de sua formação e de sua aplicação empírica.

\section{Referências}

ARISTÓTELES. Metafísica. Edição Trilíngue trad. esp.

Valentín García Yebra, trad. lat. Guillermo de Moerbeke. 2 ed. Madrid: Gredos, 1998.

HEIDEGGER, Martin. Kant y el problema de la Metafísica, trad. Gred Ibscher Roth. México: Fondo de Cultura Económica, 1996.

KANT, Immanuel. Kritik der reinen Vernunft. Hanburg: Felix Meiner, 2003.

KANT, Immanuel. Crítica da Razão Pura, trad. Valério Rohden e Udo Baldur Moosburger. 2 ed. São Paulo: Abril Cultural, 1983.

PLATÃO. Respublica, ed. J. Burnet, Platonis opera, vol. 4. 
Oxford: Clarendon Press, 1902.

PLATÃO, República, trad. Carlos Alberto Nunes. 3. ed, Belém: EDUFPA, 2000.

PLATÃO, La Repúplica, edición bilíngüe, trad. José Manuel Pabón e Manuel Fernández-Galiano, Madrid: Centro de Estudios Políticos y Constitucionales, 2006.

PLATÃO. Epistulae VII, ed. J. Burnet, Platonis opera, vol. 5. Oxford: Clarendon Press, 1907.

PLATÃO. Carta VII, Edição Bilíngue, trad. José Trindade Santos e Juvino Maia Jr. São Paulo: Loyola, 2008.

${ }^{1}$ KANT, Immanuel. Kritik der reinen Vernunft. Hanburg: Felix Meiner, 2003. Citarei o referido texto de Kant com a sigla KrV seguida da paginação das edições $A$ e $B$, apesar de verificar que, no que respeita à Doutrina do Esquematismo Transcendental, a segunda edição não alterou nada do que já estava estabelecido na edição A. Para citar o texto em português, segui o mais das vezes KANT, Immanuel. Crítica da Razão Pura, trad. Valério Rohden e Udo Baldur Moosburger. 2 ed. São Paulo: Abril Cultural, 1983.

2 Gernot BÖHME. Zeit und Zahl. Studien zur Zeittheorie bei Platon, Aristoteles, Leibniz und Kant. Frankfurt: Vittorio Klostermann, 1974, p. 258, n. 1 .

${ }^{3}$ Idem, ibidem.

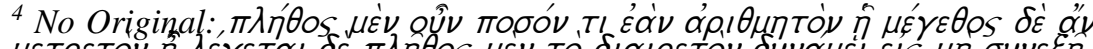

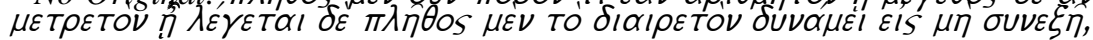

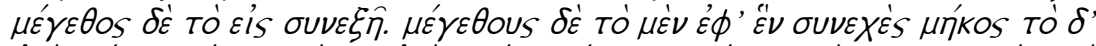

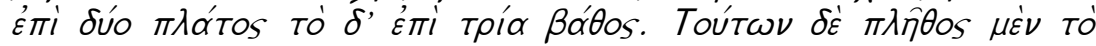

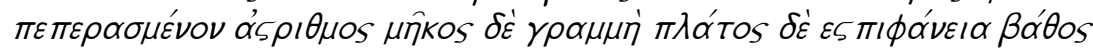
$\delta \varepsilon \dot{\varepsilon} \sigma \omega \hat{\mu \alpha}$. (ARISTÓTELES. Metafísica. Edição Trilíngue trad. esp. Valentín García Yebra, trad. lat. Guillermo de Moerbeke. 2 ed. Madrid: Gredos, 1998).

${ }^{5}$ Apresento o mapa conceitual em grego, latim e português, para que se possa ter claro a correspondência terminológica nessas línguas, a fim de que seja possível encontrar maior precisão conceitual na determinação semântica desses termos.

6 A exposição dos conceitos latinos correspondentes à conceituacão aristotélica grega seguiu aqui a tradução de Moerbecke in ARISTOTELES. Metafísica. Edição Trilíngue, trad. esp. Valentín García Yebra, trad. lat. Guillermo de Moerbeke. 2 ed. Madrid: Gredos, 1998.

${ }^{7}$ Cf. PLATÃO. Respublica, ed. J. Burnet, Platonis opera, vol. 4. Oxford: Clarendon Press, 1902, 510B 5-6.

8 Aqui se faz de fundamental importância entender como Aristóteles compreende o fato de que ser se diz de várias maneiras: cf. Metafísica $E 2$ $1026 a 33-1026 b 2$.

9 PLATÃO. Respublica, ed. J. Burnet, Platonis opera, vol. 4. Oxford: Clarendon Press, 1902. Estabeleci livremente a tradução desse texto, mas também podem ser consultadas as seguintes traduções: PLATÃO, República, trad. Carlos Alberto Nunes. 3. ed, Belém: EDUFPA, 2000; PLATÃO, La

Problemata: R. Intern. Fil. v.7, n. 1(2016), p 156-168 ISSN 2236-8612 
Repúplica, edición bilíngüe, trad. José Manuel Pabón e Manuel FernándezGaliano, Madrid: Centro de Estudios Políticos y Constitucionales, 2006.

10 PLATÃO. Epistulae VII, ed. J. Burnet, Platonis opera, vol. 5. Oxford: Clarendon Press, 1907, 342a-b. Providenciei uma tradução livre a partir do texto original, mas convém que se consulte também PLATÃO. Carta VII, Edição Bilíngue, trad. José Trindade Santos e Juvino Maia Jr. São Paulo: Loyola, 2008.

${ }^{11}$ PLATÃO. Carta VII, Edição Bilíngue, trad. José Trindade Santos e Juvino Maia Jr. São Paulo: Loyola, 2008.

${ }^{12}$ BÖHME, op. cit., p. 261

${ }^{13}$ Uma observação geral deve ser feita: o que é dito de um lado a outro no contínuo em uma dimensão é um esquema a priori de um dado no sentido externo, cuja sensação no espaço é simultânea; o mesmo podendo ser dito de cada uma das grandezas espaciais, seja como regra (na enunciação), seja como produto (na sensação).

${ }^{14}$ HEIDEGGER, Martin. Kant y el problema de la Metafísica, trad. Gred Ibscher Roth. México: Fondo de Cultura Económica, 1996, p. 90.

${ }^{15}$ Idem, ibidem.

${ }^{16}$ Idem, ibidem, p. 91.

${ }^{17}$ Idem, ibidem. 